\title{
Estrogen-mediated hemangioma-derived stem cells through estrogen receptor- $\alpha$ for infantile hemangioma
}

This article was published in the following Dove Press journal:

Cancer Management and Research

7 July 2017

Number of times this article has been viewed

\section{Ling Zhang' \\ Hai Wei Wu' \\ Weien Yuan ${ }^{2}$ \\ Jia Wei Zheng'}

'Shanghai Ninth People's Hospital, Shanghai Jiao Tong University School of Medicine, Center for Specialty Strategy Research of Shanghai Jiao Tong University China Hospital Development Institute, ${ }^{2} \mathrm{School}$ of Pharmacy, Shanghai Jiao Tong University, Shanghai, People's Republic of China
Correspondence: Weien Yuan School of Pharmacy, Shanghai Jiao Tong University, No. 800, Dongchuan Road, Shanghai 200240, People's Republic of China

Email yuanweien@I26.com

\section{Jia-Wei Zheng}

Shanghai Ninth People's Hospital, Shanghai Jiao Tong University School of Medicine, Center for Specialty Strategy Research of Shanghai Jiao Tong University China Hospital Development Institute, No. 639 Zhizaoju Road, Shanghai 2000II, People's Republic of China Email Davidzhengjw@hotmail.com
Background: Infantile hemangiomas (IHs) are the most common benign vascular tumor of infancy. They occur more frequently in female infants. The cause of hemangioma is currently unknown; however, current studies suggested the importance of estrogen (E2) signaling in hemangioma proliferation.

Methods: Hemangioma-derived stem cells (HemSCs) were cultured with estrogen for 48-72 h; the cell viability and proliferation were evaluated with the messenger RNA (mRNA) and protein expression levels of fibroblast growth factor 2 (FGF2), vascular endothelial growth factor-A (VEGF-A) and estrogen receptor- $\alpha$ (ER- $\alpha$ ), by application of several in vitro assays, such as methyl thiazolyl tetrazolium (MTT), reverse transcriptase-polymerase chain reaction (RT-PCR), real-time PCR, enzyme-linked immunosorbent assay (ELISA) and Western blotting. Also, the cell population's response to external estrogen was investigated by in vivo experiments. HemSCs and human umbilical vein endothelial cells (HUVECs) were mixed and injected subcutaneously into 20 flank of BALB/c-nu mice, which were randomly divided into 5 groups based on different E2 treatment doses (0, 0.01, 0.1 and $1 \mathrm{mg}$, respectively), $0.1 \mathrm{mg}$ dimethyl sulfoxide (DMSO) as control. Each group of mice were treated intramuscularly every week, then 2 and 4 weeks later, the subcutaneous implants were harvested and evaluated the tumor tissues with microvessel density (MVD) assay and immunohistochemistry.

Results: The study demonstrated that application of E2 increased the expression of FGF2, VEGF-A, and ER- $\alpha$ in HemSCs with the optimal concentration from $10^{-9}$ to $10^{-5} \mathrm{M}$. Two-week treatment of E2 promoted expression of VEGF-A and FGF2 in HemSCs culture. Morphological, histological and immunohistological improvements were observed in vivo using murine IH model in which HemSCs and HUVECs were implanted into BALB/c-nu mice that were post-injected with E2. In the grafts, mean MVD was markedly increased.

Conclusion: The results suggested that $\mathrm{E} 2$ promotes angiogenesis via combination with ER- $\alpha$ to up-regulate the expression of VEGF-A in HemSCs, promoting proliferation of IHs. These findings provide critical insight into the potential mechanisms of E2 action on IHs.

Keywords: hemangioma-derived stem cells, estrogen, vascular endothelial growth factor-A, estrogen receptor- $\alpha$, infantile hemangioma

\section{Introduction}

Infantile hemangioma (IH) is the most common tumor of infancy. Frequency of cutaneous hemangiomas at head and neck is $\sim 60 \% .{ }^{1}$ Most hemangiomas begin a rapid growth shortly after birth. This early phase can last for a year, followed by a slow regression phase, which is much slower and can take $3-10$ years. ${ }^{2}$ Female infants are affected more often with IHs than males, by $3-5$ times, ${ }^{3}$ and the incidence of IH increased in premature 
infants. ${ }^{4}$ The detailed cause of the female preponderance is not yet understood. However, several studies have suggested that estrogen (E2) can attribute to the female preponderance and the E2 signaling is important in angiogenesis. ${ }^{5}$ Previous reports had shown that the level of E2 in healthy children was significantly lower than that in IH patients, ${ }^{6}$ and estrogen receptors (ERs) could be found in the hemangioma tissue. ${ }^{7}$ Some studies described that the levels of serum E2 and ERs in the proliferating IH tissue are observably higher than those in involuting phase. ${ }^{8} \mathrm{E} 2$ has neovascularization effects mediated by ERs. The effects of E2 on endothelial cell growth and function may play an important role. ${ }^{9}$ By now, there are some research that suggested that $\mathrm{E} 2$ plays a potential role in the development of IHs, mainly by regulating some key angiogenic factors, including vascular endothelial growth factor-A (VEGF-A) and fibroblast growth factor 2 (FGF2). To reveal whether $\mathrm{E} 2$ and their receptor have direct effect on IHs, we investigated the effect of E2 in apoptosis, growth and expression of angiogenic factors of hemangioma-derived stem cells (HemSCs) using both in vitro and in vivo models.

\section{Materials and methods}

\section{Cell culture and cell proliferation analysis}

HemSCs were isolated from Chinese proliferating hemangioma tissues by CD133 immunomagnetic beads. Human umbilical vein endothelial cells (HUVECs) and normal human dermal fibroblasts (NHDFs) were isolated and pooled from fresh tissues using the procedure described by Greenberger et al. ${ }^{10}$ Cells were cultured in endothelial basal medium (EBM-2; CC-3162; Lonza, Basel, Switzerland) supplemented with $20 \%$ fetal bovine serum (FBS) and SingleQuot (CC-4176; Lonza). Each type of single-cell suspension was plated on to 96-well plates at a density of 4000 cells/well in $100 \mu \mathrm{L}$ complete medium. All cells were incubated in a $5 \%$ carbon dioxide-humidified atmosphere at $37^{\circ} \mathrm{C}$ for $24 \mathrm{~h}$. Cells were then treated for $48 \mathrm{~h}$ with different concentrations of E2: $0,10^{-9}, 10^{-8}, 10^{-7}, 10^{-6}$ and $10^{-5} \mathrm{M}$ (Sigma-Aldrich, St Louis, MO, USA) in EBM-2 medium without FBS and supplemented with SingleQuots. Four duplicate wells were used for each experimental and control group. Cell proliferation was evaluated at different time points (from 1 to 7 days) with the methyl thiazolyl tetrazolium (MTT) assay (Sangon Biotech, Shanghai, China). A total of $20 \mu \mathrm{L}$ MTT solution was added to each well, and the cells were incubated for an additional $4 \mathrm{~h}$ before the supernatant was removed and $150 \mu \mathrm{L}$ of dimethyl sulfoxide (DMSO) was added to each well. The optical density of each well was detected at $490 \mathrm{~nm}$ with a microplate reader (Tecan, Männedorf, Switzerland).

\section{RNA isolation and reverse transcriptase- polymerase chain reaction (RT-PCR), real-time PCR and enzyme-linked immunosorbent assay (ELISA)}

A quantitative real-time RT-PCR assay was used to quantify VEGF-A and FGF-2 messenger RNA (mRNA). Media containing E2 were washed out, and all cells were serum starved for $24 \mathrm{~h}$ before harvesting RNA from cells. Total RNA was extracted using Trizol according to the manufacturer's instructions. Isolated RNA was converted to complementary DNA (cDNA) using Ex Taq reverse transcriptase enzyme (reverse transcription reagents; Takara, Osaka, Japan). All primers for the RT-PCR and real-time PCR were designed by Sangon Biotech. The gene expression level for VEGF-A was amplified by primers 5' GCG GAT CAA ACC TCA CCA AG 3' and 5' GCT TTC GTT TTT GCC CCT TTC 3' and that for FGF-2 was amplified by primers 5'AGT GTG TGC TAA CCG TTA CCT 3' and 5' ACT GCC CAG TTC GTT TCA GTG 3'. Reactions were carried out for 38 cycles with an annealing temperature of $65^{\circ} \mathrm{C}$. An ELISA was performed with the use of VEGF-A and FGF-2 (R\&D Systems, Minneapolis, MN, USA).

\section{Western blotting}

HemSCs were digested with $0.25 \%$ trypsin and then suspended in $100 \mathrm{~mL}$ lysis buffer. The lysates were solubilized in Laemmli sample boiled for $5 \mathrm{~min}$ and separated by sodium dodecyl sulfate-polyacrylamide gel electrophoresis (SDS-PAGE). Proteins were then transferred on to polyvinylidene difluoride (PVDF) membranes (Bio-Rad Laboratories, Hercules, CA, USA) and blocked with 5\% non-fat milk in phosphate-buffered saline (PBS)-Tween 20 (PBST) $(0.05 \%)$ for $1 \mathrm{~h}$ at room temperature. The membranes were blotted with the primary antibody mouse monoclonal antihuman VEGF-A or FGF2 antibody (1:500; Peprotech, Rocky Hill, NJ, USA) at $4^{\circ} \mathrm{C}$ overnight under agitation. Membranes were then washed 3 times with PBS, followed by $1 \mathrm{~h}$ incubation with secondary antibodies (1:500; Abcam, Cambridge, UK) in darkness and subsequently washed 3 times with PBST. Bands were visualized using the Odyssey Infrared Imaging System (LI-COR Biosciences, Lincoln, NE, USA).

\section{Murine hemangioma model}

This research was conducted in the Ninth People's Hospital, Shanghai Jiao Tong University School of Medicine, China, and approved by the ethics committee of Shanghai Jiao Tong University. The experiments were performed in accordance 
with the approved protocols, and the animals received good human care. The methods were also carried out in accordance with the approved guidelines. The human subject protocol was approved by the Committee on Clinical Investigation. Clinical diagnoses of IH were confirmed by histologic and immunochemical analysis carried out by the Department of Oral-Maxillofacial, Head and Neck Surgery at the Ninth People's Hospital Shanghai. Fresh tissue was harvested upon the surgical removal or sampling of proliferating IHs, HUVECs and NHDFs under a human subject protocol, which was approved by the ethics committee at the Ninth People's Hospital, Shanghai Jiao Tong University. Informed consent was obtained from parents/guardians of all the participants, in accordance with The World Medical Association Declaration of Helsinki. All animal studies were conducted in accordance with the Animal Experimental Ethical Inspection guidelines of Shanghai and were approved by the Institutional Animal Care and Use Committee at the Ninth People's Hospital, Shanghai Jiao Tong University.

The murine model of $\mathrm{IH}$ was produced, as described previously, ${ }^{11}$ with $2 \times 10^{7}$ HemSCs and $1 \times 10^{7}$ HUVECs per mouse. Cells were mixed, sedimented, resuspended in $200 \mu \mathrm{L}$ Matrigel (BD Biosciences, San Jose, CA, USA) and injected subcutaneously into the backs of BALB/C-nu mice (4 weeks, male). Microvessel density (MVD) was quantified as described previously. ${ }^{12}$ Values that are reported for each experimental condition correspond to the average values obtained from all the individual mice. Mice were purchased from Shanghai Laboratory Animal Center. This study was approved by the Animal Ethics Committee of the Ninth People's Hospital, Shanghai Jiao Tong University School of Medicine.

\section{Immunohistochemical analyses of VEGF-A and FGF2}

Mixed HemSCs and HUVECs $\left(2 \times 10^{7}\right.$ and $1 \times 10^{7}$, respectively, in $200 \mu \mathrm{L}$ Matrigel) were injected into 4-week-old mice. All mice were randomly divided to 5 groups ( $\mathrm{n}=5$ for each group) treated with different amounts of E2 $(0,0.01,0.1,1 \mathrm{mg})$ intramuscularly every week, control group administered with $0.1 \mathrm{mg}$ DMSO instead. The subcutaneous implants were harvested at 1, 2 and 4 weeks, for hematoxylin and eosin (H\&E) staining and MVD analysis. Immunohistochemical staining was performed on cryosections as follows: slides were fixed with $4 \%$ polyoxymethylene, blocked with $5 \%$ serum and the antigens repaired for $10 \mathrm{~min}$. Sections were then incubated with glucose transporter-1 (Glut-1) antibodies at titer of $1: 50$ (Abcam) for $24 \mathrm{~h}$ at $4^{\circ} \mathrm{C}$, followed by second antibodies (1:1000; Abcam) for $20 \mathrm{~min}$ at $37^{\circ} \mathrm{C}$.

\section{Laser scanning confocal microscope of CD3I and ER- $\alpha$}

Mixed HemSCs and HUVECs with the same quantity and proportion as those used in the murine IH model were injected into 4-week-old mice ( $200 \mu \mathrm{L}$ Matrigel/animal), which were treated with $0.1 \mathrm{mg}$ E2. One week later, graft was harvested. Sections of CD31 and ER- $\alpha$ were investigated by laser scanning confocal microscope.

\section{Results \\ Estrogen promotes HemSC and HUVEC proliferation}

The HemSCs and HUVECs proliferate at similar rate under our culture condition. Under light microscopy, the cell density of the HemSCs dramatically increased on the 4th day and continued growing on day 6 and day 8 (as shown in Figure 1A). Also, HUVECs' obvious growth was from day 3, day 5 and day 7 (Figure 1B). Statistical result of the cell density over culture days was shown as OD in Figure 1C. E2 increased the growth of HemSCs, HUVECs and NHDFs as low as $10 \mathrm{nM}$ at day 3. This enhancement is in a dose-dependent manner from $10 \mathrm{nM}$ to $1 \mu \mathrm{M}$ (Figure 1D). Treatment with NHDFs was used as the baseline for the cell viability assay. Treatment with $10 \mathrm{nM}$ E2 increased the cell viability of both HUVECs and HemSCs to $\sim 20 \%$ and $1 \mu \mathrm{M}$ E2 increased the cell viability for almost $80 \%$. Concentrations $>1 \mu \mathrm{M}$, such as $10 \mu \mathrm{M}$ and $100 \mu \mathrm{M}$, did not increase the cell viability further but decreased a little bit to $\sim 10 \%(P>0.05)$.

\section{VEGF-A was up-regulated with E2 treatment in HemSCs}

Consistent with the result reported by Greenberger et al, ${ }^{10}$ the HemSCs expressed higher level of VEGF-A mRNA than NHDFs and HUVECs did. E2 treatments $(10 \mathrm{nM}$ to $10 \mu \mathrm{M})$ dramatically increased the mRNA expression level of VEGF-A compared with the untreated HemSCs (Figure 2A). The maximum augment was achieved with $1 \mu \mathrm{ME} 2$ treatment, and there was no significant difference between the groups treated with $1 \mu \mathrm{M}$ and $10 \mu \mathrm{M}$ E2 $(P>0.05)$. Consistent with these results from the real-time PCR, gel electrophoresis of RT-PCR products of VEGF-A mRNA showed that the bend is obviously heavier when the $\mathrm{E} 2$ concentration was higher in the range of $10 \mathrm{nM}$ to $1 \mu \mathrm{M}$ (Figure 2B). Also, the VEGFA protein in HemSCs, which were treated with E2, was 
A

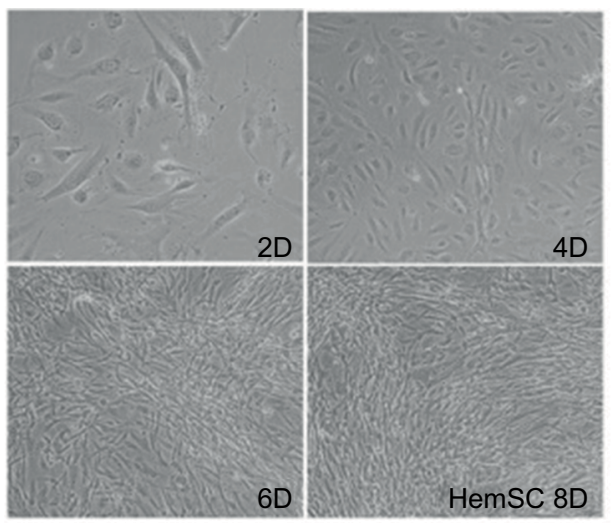

C

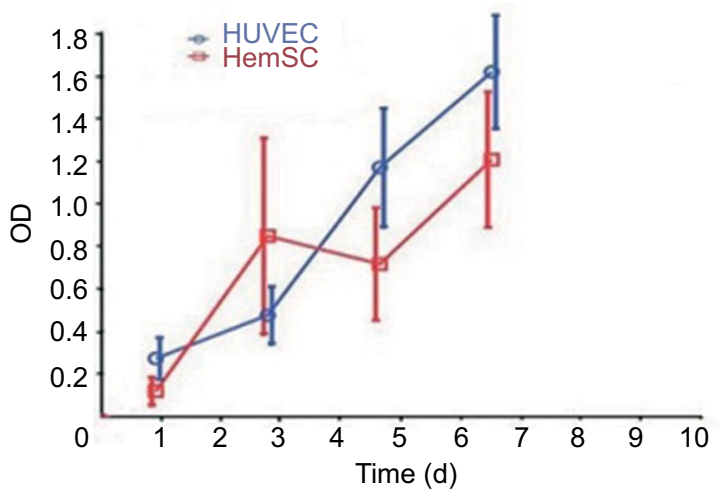

B

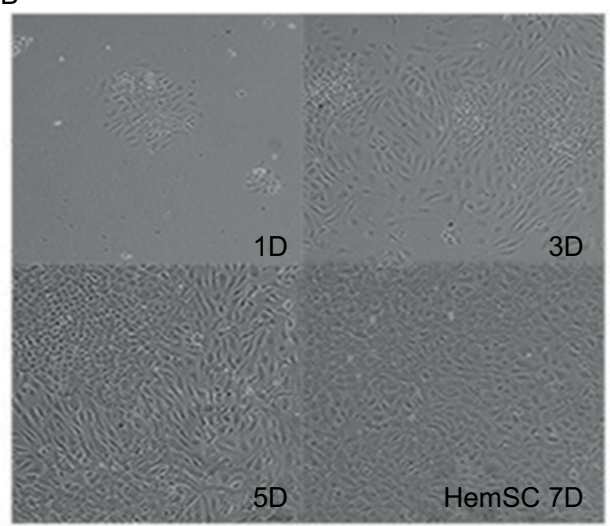

D

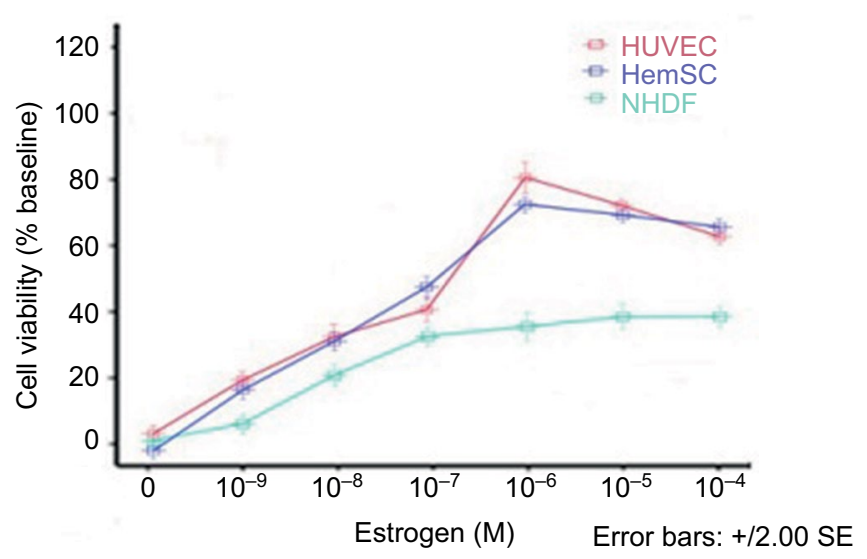

Figure I (A, B) Microscopic photos of HemSCs and HUVECs that were cultured in vitro; (C) growth curve of HUVECs and HemSCs and (D) MTT assay for cells being treated with E2 over $48 \mathrm{~h}$.

Abbreviations: HemSCs, hemangioma-derived stem cells; HUVECs, human umbilical vein endothelial cells; MTT, methyl thiazolyl tetrazolium; OD, optical density; NHDF, normal human dermal fibroblast; $d$, days.

dramatically up-regulated, compared to the untreated control group (Figure 2C and D). All these results confirmed that $10 \mathrm{nM} \mathrm{E} 2$ is enough to promote the expression of VEGF-A in both mRNA and protein levels, and this promotion was dose dependent up to, but not beyond, $1 \mu \mathrm{M}$.

\section{Effect of E2 on FGF2 expression by HemSCs}

It has been recognized that FGF2 plays an important role in cell proliferation, so we also checked the expression of FGF2 level in HemSCs after the E2 treatment. Similar to VEGF-A, RT-PCR results showed that the expression of FGF2 mRNA is significantly enhanced by $10 \mathrm{nM} \mathrm{E} 2$ (Figure 2B). The band was heavier in the range of $10 \mathrm{nM}$ to $1 \mu \mathrm{M}$ but lighter when the concentration of E2 is $>1 \mu \mathrm{M}$. Western blot analysis consistent with the results of RT-PCR, notable increasing of FGF2 protein levels was observed from $10 \mathrm{nM}$ to $10 \mu \mathrm{M}$ of E2 treatments. But there was no significance between groups treated with 1 and $10 \mu \mathrm{M}$ E2 (Figure 2D). These results sug- gested that E2 has comparable augment for expression of both FGF2 and VEGF-A in HemSCs.

\section{Effect of E2 on tumor angiogenic factors in the murine $\mathrm{IH}$ model}

Previous studies showed that tumor development was significantly correlated with MVD, so we investigated the MVD by $H \& E$ staining in the murine tumors of $\mathrm{IH}$ mice after intramuscular injection of E2 (Figure 3). We found that E2 treatment significantly increased the MVD with a dose of $0.01 \mathrm{mg}$ for a week. And the maximum MVD was achieved with $0.1 \mathrm{mg}$ E2 treatment for 2 weeks $(P<0.05$; Table 1$)$. Immunohistochemical staining showed that Glut-1 was highly expressed in the graft injected with E2 and localized at cytoplasm or lumen of blood vessel in endothelial cells (Figure 3J, K and L). In our experiments, injection of E2 did not enlarge the volume of graft obviously ( $P>0.05$; Table 2$)$. We also checked the expression of CD31 and ER- $\alpha$ in the draft from the E2-treated $\mathrm{IH}$ mice by immunostaining and 
A

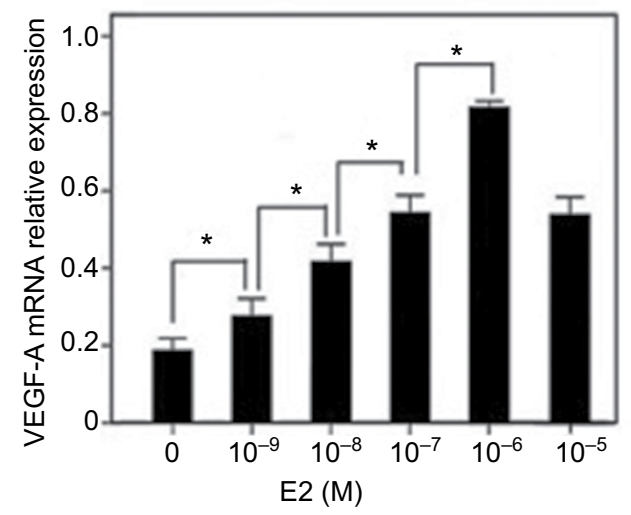

C

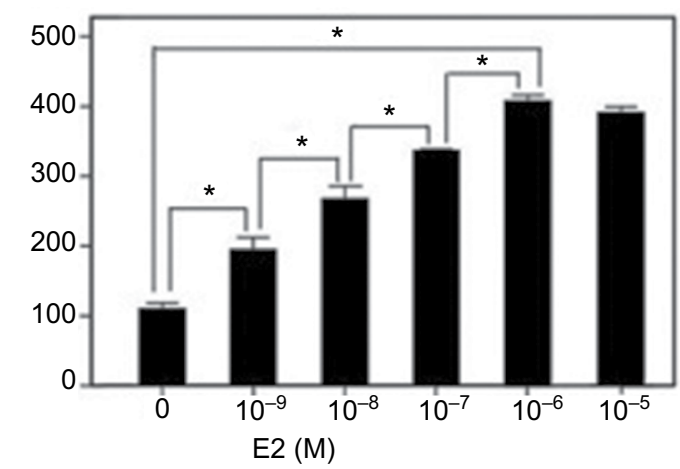

B

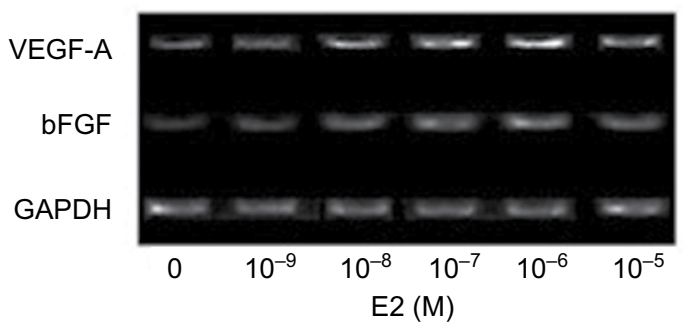

D

VEGF-A

bFGF

GAPDH

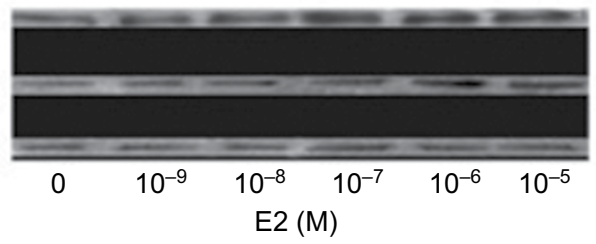

Figure 2 (A) Real-time PCR analysis of VEGF-A mRNA transcript levels; (B) RT-PCR showing increase in mRNA expression of VEGF-A with increasing concentration of E2 (*P<0.05); (C) ELISA of VEGF-A and FGF2 in supernatants of HemSCs treated with different concentrations of E2. Note the dose-dependent promotion of VEGF-A and FGF2 secretion and (D) Western blot of VEGF-A and FGF2 protein in HemSCs treated with different concentrations of E2.

Abbreviations: PCR, polymerase chain reaction; mRNA, messenger RNA; RT, reverse transcriptase; HemSCs, hemangioma-derived stem cells; FGF2, fibroblast growth factor 2; VEGF-A, vascular endothelial growth factor-A; bFGF, basic fibroblast growth factor.

laser scanning confocal microscope. Our results showed that CD31 and ER- $\alpha$ were strongly positively expressed on the cytomembrane, while 4',6-diamidino-2-phenylindole (DAPI) showed nucleus in blue (Figure 4A and B).

\section{Discussion}

The effect of E2 is widely investigated, but very little is known about the mechanisms of E2 in IH. Previous studies in this field showed that $\mathrm{E} 2$ increased the mitotic rate and enhanced the DNA synthesis in endothelial cells. This enhanced mitotic rate may attribute to the increased cell permeability to proteins and other molecules. ${ }^{13}$ It has been shown that E2 plays a role in the pathogenesis of hemangiomas formation by inhibiting endothelial cell apoptosis and inducing the expression of vascular adhesion molecules and integrins. Also, it has been reported that E2 induced expression of other angiogenic growth factors, such as basic fibroblast growth factor, insulin-like growth factor and transforming growth factor- $\beta$, and regulated proliferation of IH formation. ${ }^{14}$ Our studies showed that E2 plays a pivotal role in the development of IHs. For the premature infants, especially the infants with low birth weight, the metabolism of the E2 may be slow and insufficient, and the abnormal high level of E2 up-regulated the angiogenic factors, such as VEGF-A and FGF2. ${ }^{15}$ This results in the promotion of angiogenesis eventually. Long-term effects of E2 are characterized by inducing proliferation of endothelial cells in IH patients. ${ }^{16}$ We found that E2 significantly promoted the proliferation of HemSCs and HUVECs in a dose-dependent manner. As one of the angiogenic factors, VEGF-A promotes vascular endothelial cells proliferation, migration and assembly into new vessels. It played an important role in IHs formation. ${ }^{17}$ In this study, we found that E2 promoted HemSCs differentiation into vascular endothelial cells, which proliferate, circulate and participate in the development of vascular networks. E2 also increased the expression of VEGF-A and FGF2, which contribute to the early growth of IHs. It is anticipated that they will also contribute to vasculogenesis and extend the time of vasculogenesis in the involution.

VEGF-A and FGF2 are the main growth factors that promote vasculogenesis in proliferating hemangiomas. ${ }^{18}$ Importantly, VEGF-A and FGF2 are proangiogenic growth 

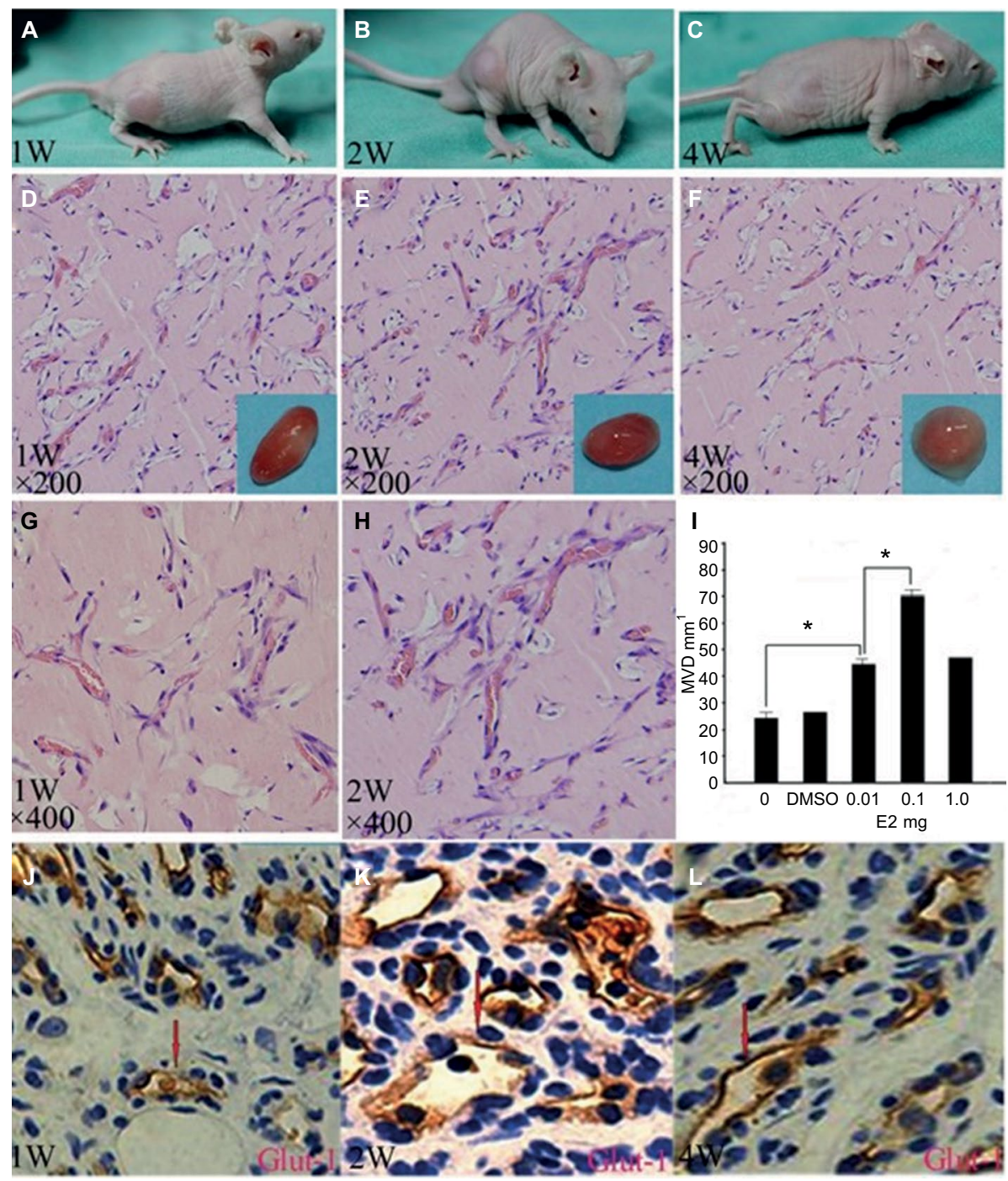

Figure 3 (A-C) E2 induces tumorigenesis in the in vivo IH model (IW, 2W and 4W); (D-F) representative H\&E-stained section (IW, 2W and 4W, $\times 200)$; (G, H) representative H\&E-stained section (IW and 2W, $\times 400)$; (I) statistical comparison of MVD in murine tumor tissue $(* P<0.05)$; (J-L) immunohistochemical staining of Glut-I (IW, $2 \mathrm{~W}$ and $4 \mathrm{~W})$.

Abbreviations: $\mathrm{IH}$, infantile hemangioma; W, weeks; H\&E, hematoxylin and eosin; MVD, microvessel density; DMSO, dimethyl sulfoxide.

Table I Volume of tumor $\left(\mathrm{mm}^{3}\right)$

\begin{tabular}{llllll}
\hline Time & Group I & Group 2 & Group 3 & DMSO & Control \\
\hline IW & $24.9 \pm 2.6$ & $25.1 \pm 1.1$ & $25.1 \pm 1.3$ & $24.2 \pm 1.4$ & $23.5 \pm 1.8$ \\
2W & $25.5 \pm 1.6$ & $25.9 \pm 0.8$ & $24.7 \pm 1.0$ & $23.9 \pm 2.1$ & $24.5 \pm 1.7$ \\
4W & $26.0 \pm 0.7$ & $26.1 \pm 1.2$ & $23.7 \pm 1.1$ & $22.9 \pm 1.3$ & $25.7 \pm 1.9$ \\
\hline
\end{tabular}

Abbreviations: DMSO, dimethyl sulfoxide; $\mathrm{W}$, weeks.

factors that stimulate the proliferation and differentiation of ECs and promote vasculogenesis. ${ }^{19}$ We detected high levels of VEGF-A and FGF2 in the proliferating IH tissues. We showed that even a low concentration of $\mathrm{E} 2(10 \mathrm{nM})$ is capable of up-regulating the expression of both mRNA and protein of VEGF-A in HemSCs. We also found that E2 up-regulated the expression of FGF2 in HemSCs; however, this effect is less pronounced when the concentration was $>1 \mu \mathrm{M}$. Specifically,
Table 2 Results of MVD in 5 groups $\left(\mathrm{mm}^{2}\right)$

\begin{tabular}{llllll}
\hline Time & Group I & Group 2 & Group 3 & DMSO & Control \\
\hline IW & $59.1 \pm 0.6$ & $65.3 \pm 2.1$ & $66.2 \pm 1.5$ & $34.2 \pm 0.4$ & $40.5 \pm 1.7$ \\
2W & $62.5 \pm 1.1$ & $69.9 \pm 1.8$ & $68.7 \pm 1.1$ & $31.9 \pm 1.3$ & $43.5 \pm 1.2$ \\
4W & $64.0 \pm 0.9$ & $68.9 \pm 1.7$ & $60.7 \pm 1.3$ & $27.3 \pm 1.2$ & $37.7 \pm 1.8$ \\
\hline
\end{tabular}

Abbreviations: MVD, microvessel density; DMSO, dimethyl sulfoxide; $W$, weeks.

we showed that the murine IH model has the most MVD when treated with $0.1 \mathrm{mg}$ E2 for 2 weeks. This clearly demonstrated that E2 played a potential role in the development of IHs by regulating the key angiogenic factors VEGF-A and FGF2.

It has been reported that E2 promotes cell growth in angiogenesis leading to repairs in the aged vascular tissues by ER- $\alpha .{ }^{20}$ In this study, there was a clear expression of ER- $\alpha$ in the HemSC graft. And this expression of ER- $\alpha$ was 
A

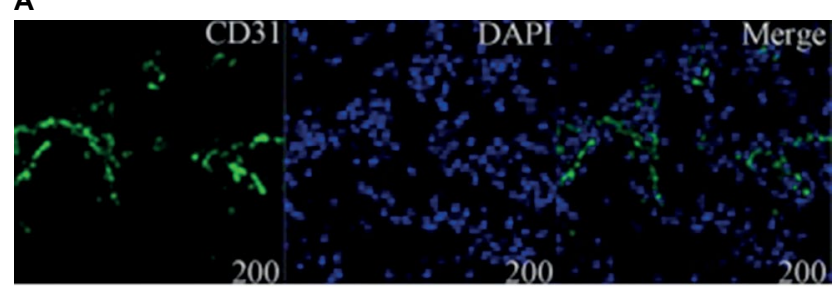

B

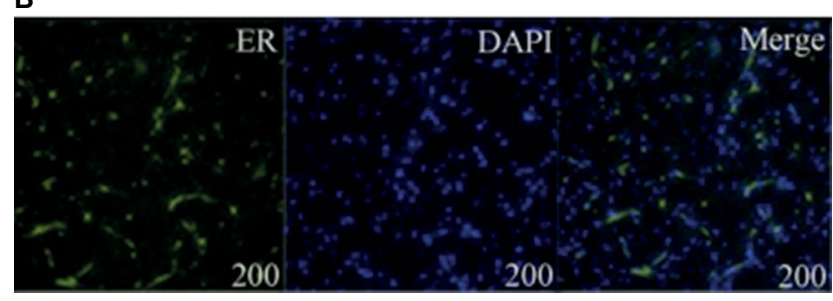

Figure 4 (A, B) Laser scanning confocal microscope of CD3I and ER- $\alpha$. Immunofluorescence analysis showed that DAPI was stained blue in the nucleus and CD3 I and ER- $\alpha$ were positively expressed in the cytomembrane.

Abbreviation: ER, estrogen receptor.

up-regulated when the concentration of E2 was increased. Similar results were observed for the protein VEGF-A. So our hypothesis is that E2 up-regulated the expression of VEGF-A by combining with ER- $\alpha$. It has been reported that ERs are also involved in this process that is induced by vascular angiogenic growth factors. ${ }^{21}$ And our results are consistent with previous report. ECs lining the dilated venules of IHs have been found to contain enhanced fibrinolytic activity. When E2 binds to its receptors in IH patients, it induces proliferation of the capillary, and acting through the ER may up-regulate this locally magnified, cell-associated fibrinolytic activity. ${ }^{22}$ Based on these, we conclude that E2 promotes EC-mediated capillary formation by an activated ER- $\alpha$. The ER- $\alpha$ agonists promoted EC activity and lead to rapid capillary formation. Previous reports showed that ER- $\alpha$ mediated E2-induced VEGF-A release, inhibited the cell growth of vascular smooth muscle and lesion formation and induced endothelial cell growth. ${ }^{23-28}$ Serum E2 may be the most potential marker for diagnosing hemangiomas and determining the proliferating stage of hemangiomas. Here, we provided evidence that E2 promoted HemSC-mediated capillary formation via ER- $\alpha$ and the stimulatory actions of E2 are mediated by activated ER- $\alpha$.

Our experiment also showed that E2 promoted proliferation of HemSCs. It promoted angiogenesis, and this role was maintained in the proliferation phase, until the serum E2 decreased in the involuted phase.

Current work may lead a new direction in the study of mechanisms for proliferation of hemangiomas formation. Future studies will further investigate the detailed signaling pathways involved in the E2-induced IHs. A more patientspecific therapy can be designed to prevent the proliferation of hemangiomas formation when identifying the specific target as a potential target in the E2 pathway. Especially, further studies of the detailed mechanisms for E2-induced IHs will produce effective E2 and ER antagonists as new medication.

\section{Acknowledgment}

All phases of this study were sponsored by the National Natural Science Foundation of China (81541041 and 81570992) and the Interdisciplinary of Shanghai Jiao Tong University (project number YG2015MS06).

\section{Author contributions}

LZ and WY participated in designing of the experiment, searched databases, extracted and assessed studies and helped to draft the manuscript. LZ and HWW participated in the conceptualization and design of the experiment, data extraction and analysis and wrote the manuscript. WY and JWZ conceived the initial idea and the conceptualization, participated in the data extraction and analysis and revised the manuscript. All authors read and approved the final manuscript.

\section{Disclosure}

The authors report no conflicts of interest in this work.

\section{References}

1. Drolet BA, Esterly NB, Frieden IJ. Hemangiomas in children. $N$ Engl J Med. 1999;341(3):173-181.

2. Janmohamed SR, Madern GC, de Laat PC, Oranje AP. Educational paper: therapy of infantile haemangioma - history and current state (part II). Eur J Pediatr. 2015;174(2):259-266.

3. Zhang L, Yuan WE, Zheng JW. Pharmacological therapies for infantile hemangiomas: a clinical study in 853 consecutive patients using a standard treatment algorithm. Sci Rep. 2016;6:21670.

4. Darrow DH, Greene AK, Mancini AJ, Nopper AJ; Section on Dermatology, Section on Otolaryngology-Head and Neck Surgery, and Section on Plastic Surgery. Diagnosis and management of infantile hemangioma. Pediatrics. 2015;136(4):1060-1104.

5. Baruscotti I, Barchiesi F, Jackson EK, et al. Estradiol stimulates capillary formation by human endothelial progenitor cells: role of ER- $\alpha / \beta$, heme oxygenase-1 and tyrosine kinase. Hypertension. 2010;56:397-404.

6. Sasaki GH, Pang CY, Wittliff JL. Pathogenesis and treatment of infant skin strawberry hemangiomas: clinical and in vitro studies of hormonal effects. Plast Reconstr Surg. 1984;73(3):359-370.

7. Barzilay D, Metzker A, Brenner S. Some considerations on hemangioma. Skinmed. 2002;1(1):47-49.

8. Yu Y, Fuhr J, Boye E, et al. Mesenchymal stem cells and adipogenesis in hemangioma involution. Stem Cells. 2006;24(6):1605-1612.

9. Jia J, Zhao YF, Zhao JH. Potential roles of allograft inflammatory factor-1 in the pathogenesis of hemangiomas. Med Hypotheses. 2007;68(2): 288-290.

10. Greenberger S, Boscolo E, Adini I, Mulliken JB, Bischoff J. Corticosteroid suppression of VEGF-A in infantile hemangioma-derived stem cells. N Engl J Med. 2010;362(11):1005-1013. 
11. Zhang L, Mai HM, Zheng J, et al. Propranolol inhibits angiogenesis via down-regulating the expression of vascular endothelial growth factor in hemangioma derived stem cell. Int J Clin Exp Pathol. 2013;7(1): 48-55.

12. Khan ZA, Boscolo E, Picard A, et al. Multipotential stem cells recapitulate human infantile hemangioma in immunodeficient mice. J Clin Invest. 2008;118(7):2592-2599.

13. Greenberger S, Bischoff J. Pathogenesis of infantile haemangioma. $\mathrm{Br}$ J Dermatol. 2013;169(1):12-19.

14. Ferrara N, Kerbel RS. Angiogenesis as a therapeutic target. Nature. 2005;438(7070):967-974.

15. Ritter MR, Reinisch J, Friedlander SF, Friedlander M. Myeloid cells in infantile hemangioma. Am J Pathol. 2006;168(2):621-628.

16. Barnes CM, Huang S, Kaipainen A, et al. Evidence by molecular profiling for a placental origin of infantile hemangioma. Proc Natl Acad Sci US A. 2005;102(52):19097-19102.

17. Greenberger S, Bischoff J. Infantile hemangioma-mechanism(s) of drug action on a vascular tumor. Cold Spring Harb Perspect Med. 2011;1(1):1-10.

18. Chen TS, Eichenfield LF, Friedlander SF. Infantile hemangiomas: an update on pathogenesis and therapy. Pediatrics. 2013;131(1): 99-108.

19. Uebelhoer M, Boon LM, Vikkula M. Vascular anomalies: from genetics toward models for therapeutic trials. Cold Spring Harb Perspect Med. 2012;2(8):1-21.
20. Gupta PB, Kuperwasser C. Contributions of estrogen to ER-negative breast tumor growth. J Steroid Biochem. 2006;102(1-5):71-78.

21. Dubey RK, Imthurn B, Barton M, Jackson EK. Vascular consequences of menopause and hormone therapy: importance of timing of treatment and type of estrogen. Cardiovasc Res. 2005;66(2):295-306.

22. Jameson JJ, Cave DR. Hormonal and antihormonal therapy for epistaxis in hereditary hemorrhagic telangiectasia. Laryngoscope. 2004;114(4):705-709.

23. Dubey RK, Jackson EK. Estrogen-induced cardiorenal protection: potential cellular, biochemical, and molecular mechanisms. Am J Physiol Renal Physiol. 2001;280(3):365-388.

24. Mendelsohn ME, Karas RH. The protective effects of estrogen on the cardiovascular system. N Engl J Med. 1999;340(23):1801-1811.

25. Losordo DW, Inser JM. Estrogen and angiogenesis: a review. Arterioscler Thromb Vasc Biol. 2001;21(1):6-12.

26. Rosselli M, Imthurn B, Keller PJ, Jackson EK, Dubey RK. Circulating nitric oxide (nitrite/nitrate) levels in postmenopausal women substituted with 17 beta-estradiol and norethisterone acetate. A two-year follow-up study. Hypertension. 1995;25(4 pt 2):848-853.

27. Dzau VJ, Gnecchi M, Pachori AS, Morello F, Melo LG. Therapeutic potential of endothelial cells in cardiovascular diseases. Hypertension. 2005;46(1):7-18.

28. Pare G, Krust A, Karas RH, et al. Estrogen receptor- $\alpha$ mediates the protective effects of estrogen against vascular injury. Circ Res. 2002;90(10):1087-1092.
Cancer Management and Research

\section{Publish your work in this journal}

Cancer Management and Research is an international, peer-reviewed open access journal focusing on cancer research and the optimal use of preventative and integrated treatment interventions to achieve improved outcomes, enhanced survival and quality of life for the cancer patient. The manuscript management system is completely online and includes
Dovepress

a very quick and fair peer-review system, which is all easy to use. Visit $\mathrm{http}: / / \mathrm{www}$.dovepress.com/testimonials.php to read real quotes from published authors. 